\title{
Development of a Shared Vision for Flexible Inter-Institutional Professional Development using the OOFAT Model
}

\author{
Dr Laura Costelloe ${ }^{1}$ \\ Dr Chrissi Nerantzi ${ }^{2}$ \\ Dr Emma O'Brien ${ }^{1}$ \\ Jean Reale ${ }^{l}$ \\ Dr Íde O'Sullivan ${ }^{3}$
}

\author{
${ }^{I}$ Mary Immaculate College, Ireland \\ ${ }^{2}$ Manchester Metropolitan University, United Kingdom \\ ${ }^{3}$ University of Limerick, Ireland
}

\begin{abstract}
Given the increasing pressure higher education institutions are facing, collaboration is key to increase capacity to address competing demands. The professional development (PD) of academic staff has been identified as one of the key priority areas in the modernisation of Higher Education to support them to cope with growing numbers, more diverse student groups and a dynamic environment. There is a need for a flexible approach to PD that leverages from formal and informal approaches to allow academic staff to upskill while practicing. Many Higher Education Institutes (HEIs) are collaborating in this area to exchange best practice and increase the PD activities they offer to their staff. However, each HEI has different strategies, cultures and institutional needs. To allow them to collaborate they need to develop a shared vision in the area of PD. This paper discusses the FLEXIpath project in which three HEIs are collaborating to extend their PD provision to enhance academic practice. It explores the role of a visual modelling approach, (specifically the OOFAT model), in facilitating the development of a shared roadmap for the provision of collaborative PD through negotiation and scaffolded discussion.
\end{abstract}

Keywords: Visual Representation; Academic Professional Development; Flexible Professional Development; OOFAT; Open Practice 


\section{Introduction}

This discussion paper is based on a design workshop undertaken as part of a project funded by the Irish National Forum for the Enhancement of Teaching and Learning in Higher Education entitled 'Professional Development Capacity Building in Higher Education: extending provision for national impact through a flexible pathways approach', or FLEXIpath (National Forum for the Enhancement of Teaching and Learning in Higher Education 2020). FLEXIpath aims to develop flexible pathways for those who teach in Higher Education, providing inter-institutional opportunities to gain credits or recognition for formal and informal learning undertaken to enhance academic practice. The project team sought to articulate a shared vision for the project, therefore the OOFAT model was piloted to support the project team to visualise how to progress the project beyond conceptualisation stage.

When engaging in collaboration we negotiate and agree on how to reach a common goal based on our beliefs and values (Sidner 1994). In complex situations where there are a variety of stakeholders, a number of factors come into play, particularly where an individual is representing an institution or a group of individuals, negotiation becomes increasingly difficult. This is often because they have to meet the needs of an institution, an individual as well as the other partners and they need to negotiate on a variety of levels.

It has been recognised that 'in many domains of science and technology, visualisations are seen as the most complete and explicit way of explaining things, and words become supplements, comments, footnotes, labels' (Van Leeuwen 2008, p.136). Visual representation can take the form of deliberate representation with a variety of features including text, pictorial, modelled or images (Ewenstein and Whyte 2007). Swaab et al. (2002) highlighted that visual representations are effective in developing shared mental models in a group of individuals, particularly to facilitate negotiation. In particular, visual modelling can scaffold conversation and developed a shared vision to facilitate collaborative problem solving (Black and Andersen 2012).

Indeed, some consideration has been given in the literature to how images can support the work of academic developers and others working in Higher Education (HE). There are some examples of visuals and concepts maps being used to surface conceptions of research and researchers (Bryans and Mavin 2006), to facilitate the diffusion of strategy ideas (Fenton 2007) and to highlight similarities and differences with regards to perspectives on quality and safety (Travaglia et al. 2011). Furthermore, Kinchin (2014) has explored the use of concept mapping with HE teachers to explore conceptions of learning and teaching, and with students to explore relationships between the theory and practice of biology (Kinchin 2011). Kinchin, Cabot and Hay (2008) similarly used concept maps to explore the nature of expertise in HE to support the development of an authentic pedagogy.

International Journal of Management and Applied Research, 2020, Vol. 7, No. 3 


\section{Development of a Shared Vision for Flexible Inter-Institutional Professional Development using the OOFAT Model}

The case study detailed below builds on this literature and considers how visuals specifically the OOFAT model (Orr et al. 2018; 2019) - can be used to facilitate discussions between a teaching and learning project group focused on developing a strategy and approach for flexible inter-institutional professional development.

\section{Background to the project}

Previous studies have highlighted the need for flexibility and accessibility in the provision of professional development (PD) (c.f. Teräs 2016; Botham 2018) and both new and experienced HE faculty cite time constraints as a significant barrier to engaging in PD (Brownell and Tanner 2012). The project thus responds to strong calls in the literature and from academics locally for greater flexibility in both the provision and recognition of professional learning, both formal and informal. It seeks to design flexible learning pathways for all staff who teach, taking account of the distinct contexts and needs of a diverse range of disciplines. The development of these flexible pathways takes place in tandem with the recently introduced Professional Development Framework for those who teach in Irish Higher Education (National Forum for the Enhancement of Teaching and Learning in Higher Education 2016). Consequently, FLEXIpath seeks to take account of the broad range of knowledge, skills and competences required for effective academic practice and to offer pathways to recognition and accreditation that can be mapped to the National Professional Development Framework. The project team are keen that such pathways will be 'flexible'; this includes flexibility regarding module curricula and the opportunity for academic staff to undertake professional learning in areas of interest and relevance to them. Additionally, the project seeks to identify flexible routes to accreditation and recognition, offering those who teach the opportunity to have different types of professional learning recognised. This will include Recognition of Prior Learning (both experiential and accredited) and a range of accredited offerings, from individual modules to a clear pathway to a regional doctoral qualification at Level 10 in academic practice.

The project involves collaboration among three Higher Education institutions in the Midwest region in Ireland, including Mary Immaculate College (a College of Education), the University of Limerick and Limerick Institute of Technology. The three institutions have a long-standing history of cooperation and collaboration in the area of teaching and learning, including an inter-institutional peer observation of teaching network, a regional teaching excellence awards scheme and monthly peer-led practice-sharing 'conversations', where academic staff are invited to share effective practice with colleagues in the other institutions. While these 'conversations' are well attended locally and are open to staff from all three institutions, the face-to-face delivery format has meant that in practice it is difficult logistically for truly interinstitutional conversations to take place on a regular basis. However, a regional teaching and learning showcase was held in 2017, with a further one-day teaching symposium planned for 2021.

The University of Limerick offers an accredited programme (Graduate Diploma/MA) in teaching, learning and scholarship to academic staff and a previously funded

International Journal of Management and Applied Research, 2020, Vol. 7, No. 3 


\section{Development of a Shared Vision for Flexible Inter-Institutional Professional Development using the OOFAT Model}

National Forum project resulted in the development of a Summer School module, which was collaboratively designed and is collaboratively delivered and assessed by academic faculty from the three institutions in the region. Limerick Institute of Technology offers staff a number of 10-credit accredited modules in the domain of blended and online learning and reflective practice and Mary Immaculate College has recently launched a 30 credit fully online Graduate Certificate in Academic Practice (Level 9). The project seeks to harness the existing formal and informal PD activities that are taking place within the region, in order to open up PD opportunities to staff in all three institutions, but also to foster greater practitioner-led practice sharing and collaboration, both locally and nationally. To achieve this goal, the project team identified the need to extend and build more blended/online formal and informal PD opportunities across the three institutions, including collaboratively developed shared modules, which incorporate opportunities for practitioner-led practice sharing, but with local accreditation. Interview and survey data collected from the three institutions confirm that faculty would welcome the opportunity to take part in an online/blended programme or to take individual modules in an online/blended format.

Following initial scoping exercises to identify institutional needs and preferences, the project team sought to develop a shared vision for flexible pathways within and across the three institutions, which would take account of local strategic priorities but harness existing regional teaching and learning networks and communities of practice. Therefore, colleagues from three institutions came together in a design workshop, facilitated by an external consultant to the project team, to develop a shared vision for these flexible pathways, building upon a long-standing history of cooperation and collaboration in the enhancement of academic practice. As outlined below, this workshop was structured around Orr, Weller and Farrow's (2018; 2019) Open, Online, Flexible and Technology-Enhanced Learning Model (OOFAT), a model originally developed for 'framing difference in three key educational processes [...] related to the potential of digitalization to make these processes more flexible and more open' (Orr et al. 2019, p.1). However, the model was used in this instance as part of a collaborative design process, to frame and guide discussions in relation to the development of a flexible, inter-institutional and regional approach to enhancing academic practice in Higher Education. Consequently, this paper seeks to propose a response to the following question: can the OOFAT model support the development of a shared vision for flexible, inter-institutional professional development in Higher Education academic practice?

\section{The design workshop}

A design workshop was offered at Mary Immaculate College in Limerick on 2 October 2019 that brought together colleagues from all three partners of the FLEXIpath project. The aim was to attempt to start articulating a shared vision and identify specific ways to collaborate in the area of professional development of staff who teach or support learning in the three participating institutions. The workshop was organised while the FLEXIpath project was under development. Data collection, via a survey instrument had been completed and the interviews for more in-depth data collection were about to

International Journal of Management and Applied Research, 2020, Vol. 7, No. 3 


\section{Development of a Shared Vision for Flexible Inter-Institutional Professional Development using the OOFAT Model}

start. In total eight individuals participated in this workshop with representation from all three institutions.

As outlined above, the recently developed model for flexible and open learning was selected for this workshop to trial its use in the context of inter-institutional professional development as a discussion tool. Specifically, Orr, Weller and Farrow's (2018; 2019) Open, Online, Flexible and Technology-Enhanced Learning Model (OOFAT) provided an appropriate scaffold to facilitate discussions during this workshop with the FLEXIpath team as it has flexibility and openness at its heart and was developed with institution-wide analysis and evaluation in mind. The OOFAT model has been used recently at the Mexico National University to review flexible and open and distance learning provision and to identify how the business model of such provision has changed and to plan for future developments (Cervantes-Perez et al. 2019). The authors acknowledge the strength of the OOFAT model as a valuable visualisation and discussion tool to map institution-wide practice. We were also keen to explore if it could be useful for the FLEXIpath project to help collaborating institutions articulate their objectives with greater clarity, focus their own priorities and identify common areas for exploration that could form the basis of their continued collective inter-institutional collaborative efforts.

The OOFAT is a conceptual model and an output of Orr, Weller and Farrow's (2018) study for the International Council for Open and Distance Education. Survey responses from 69 higher education institutions (150 responses in total from 36 countries) revealed six distinct OOFAT patterns. The role of content, delivery and recognition and their inter-relationship helped to explore the concepts of flexibility and openness within educational offers and illuminate related institutional practices and strategies. The model consists of the following nine dimensions as depicted in Figure 1, which are relevant to the learning and teaching cycle:

Figure 1: Dimensions of the OOFAT model

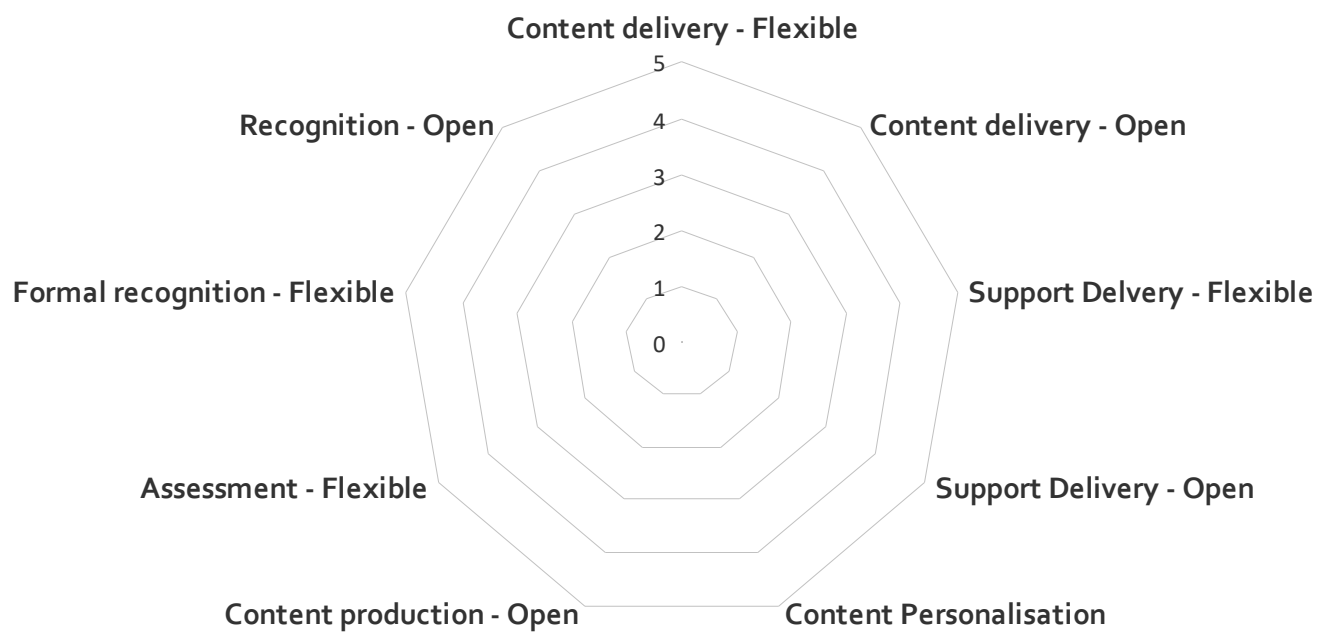

Source: Orr, Weller \& Farrow (2019)

International Journal of Management and Applied Research, 2020, Vol. 7, No. 3 
Orr, Weller and Farrow (2019) identified the following six OOFAT profiles:

- OOFAT at the centre: an integrated approach across all dimensions within the institution aligned to the institutional mission, offering open self-study that can then lead to registration on formal programmes.

- OOFAT for organisational flexibility: a wide-reaching approach at an institutional level with a focus on maximising flexibility including the assessment arrangements and open registration.

- OOFAT for a specific purpose: a focused approach to flexibility and/or openness on one specific dimension linked to a specific project, target or priority.

- Content-focused OOFAT model: a focused approach to maximise flexibility specifically linked to content that is available online and offline. Self-paced study and flexible support when needed.

- Access-focused OOFAT model: a focused approach to provide access to learning to specific groups of learners and enables self-paced self-study.

- OOFAT for multiple projects: an approach that is simultaneously focused on more than one dimensions regarding openness and/or flexibility with open and ongoing registration. These can relate to explorative applications that may inform a future institution-wide implementation.

The concepts of flexibility and openness and the opportunities these present for educational offers in higher education are at the heart of the OOFAT model together with strategies for how institutions could implement these based on specific priorities. The six OOFAT profiles identified through Orr, Weller and Farrow (2019) provide valuable insights into distinct institutional approaches.

While openness was not explicitly mentioned in the FLEXIpath project as a desired output, practice or priority, the workshop facilitator could see the potential relevance of openness to this project. Openness seems to be the ethos that underpins activities and aspirations of the project team. Therefore, the facilitator designed the workshop around the OOFAT model and used it as a scaffold in a series of activities that became the base for focused institutional and inter-institutional discussions. In these activities, flexibility and openness were considered in the context of professional development. The focus was on shaping a shared vision among FLEXIpath partners. Below is a brief overview of the workshop stages that may be of interest to others who would consider adapting this for a different context:

Stage 1: Initially, in the workshop, descriptions of the six defined OOFAT models were discussed in pairs using a speed dating approach to help participants familiarise themselves with the OOFAT model, the concepts of flexibility and openness, its specific dimensions as well as the six OOFAT profiles. During these discussions' participants started thinking about their own institution, position and relationship with FLEXIpath partner institutions and their plans for continued inter-institutional professional development and what this could look like. The discussion following this

International Journal of Management and Applied Research, 2020, Vol. 7, No. 3 


\section{Development of a Shared Vision for Flexible Inter-Institutional Professional Development using the OOFAT Model}

speed dating exercise was also very interesting and useful: it became clear that participant's definitions/understandings of 'openness' and 'flexibility' varied, with differing emphases in terms of what should be prioritised in an open and flexible approach to supporting professional learning. These discussions enabled clarification of the various domains of the OOFAT framework and to consider various examples provided by the OOFAT authors. This helped focus the later discussions as there was a clearer sense of what 'open' might constitute for the purposes of the FLEXIpath project.

Stage 2: Participants started making connections to their own institutional context, which they then had the opportunity to discuss and visualise through attempting to create their own institutional OOFAT profile. Participants were working in mixed institutional groups with each group focusing on developing an aspirational OOFAT profile for a particular institution directly linked to professional development. A participant from that particular institution led the discussions and colleagues from the other two partner institutions had the opportunity to ask questions, share ideas and help shape the profile. In order to finalise a draft OOFAT profile for each institution linked to professional development as part of the FLEXIpath project, colleagues then regrouped so that they could work in their institutional teams and help finalise their draft OOFAT profile. As evident in Figures 2-4 below, for some institutions, the conversation resulted in a review and redraft of their respective OOFAT profiles, which was a constructive activity in and of itself:

Across the three institutions, the visualisations produced by the OOFAT model pointed to a shared emphasis on flexibility and openness with regard to content delivery and support delivery. Equally, there was a common commitment to flexibility regarding formal recognition, including a shared concern with allowing multiple pathways to gaining accreditation for engagement in PD. The visualisations also highlighted that all three institutions were keen to adopt a flexible approach to assessment, although with some limitations/constraints.

Figure 2: MIC OOFAT Profile

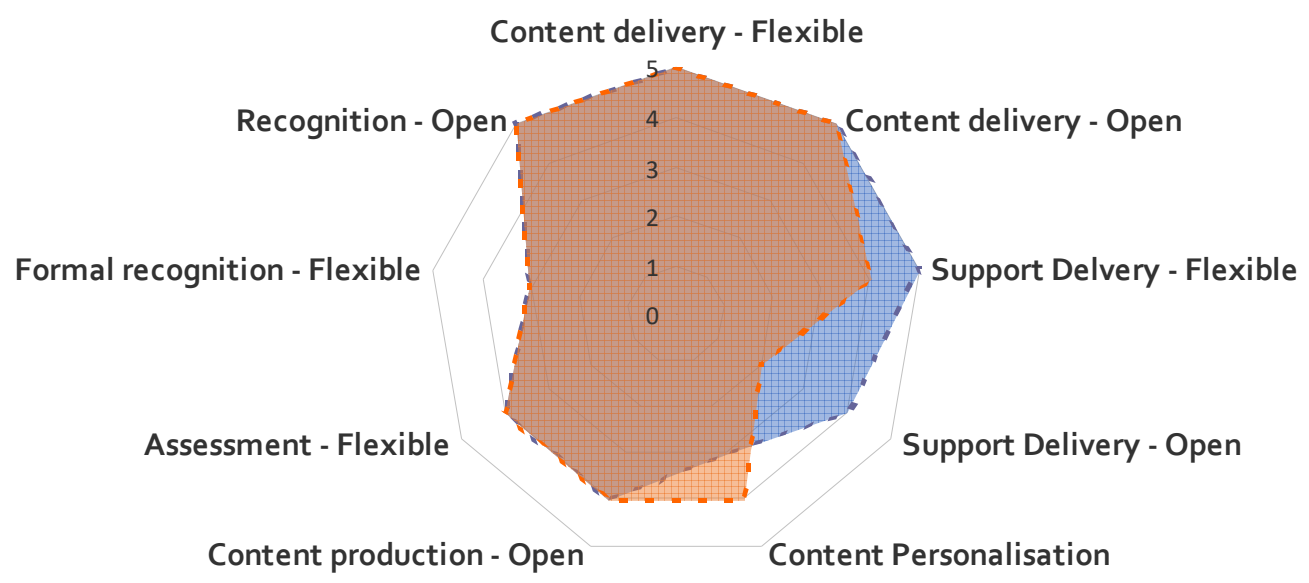

International Journal of Management and Applied Research, 2020, Vol. 7, No. 3 
Figure 3: UL OOFAT Profile

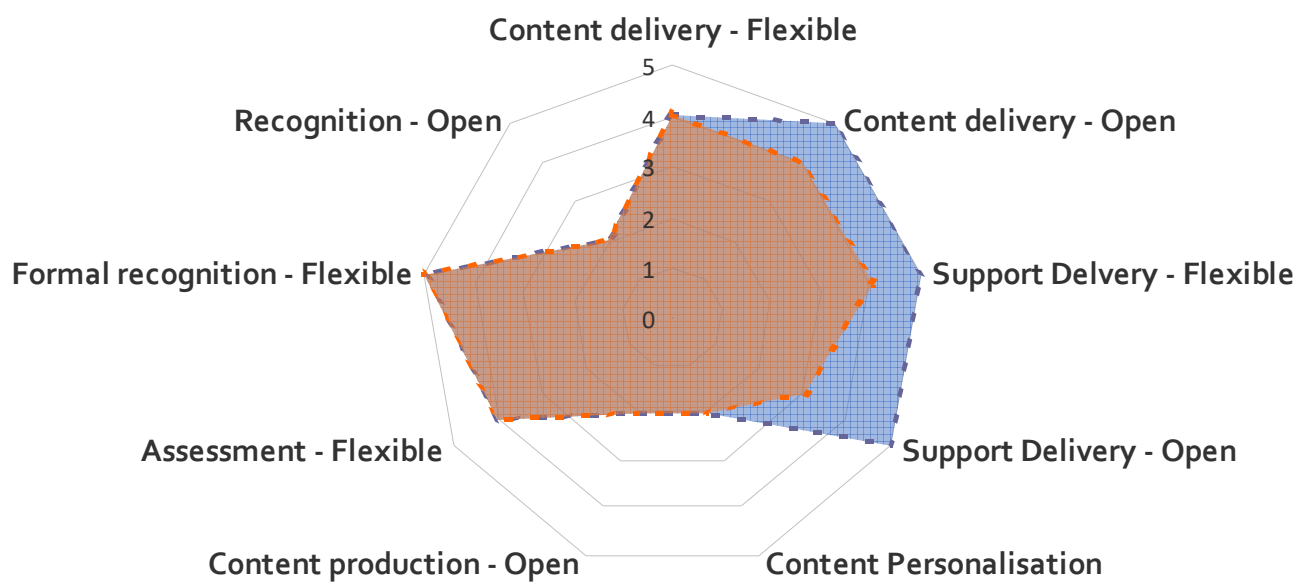

Figure 4: LIT OOFAT Profile

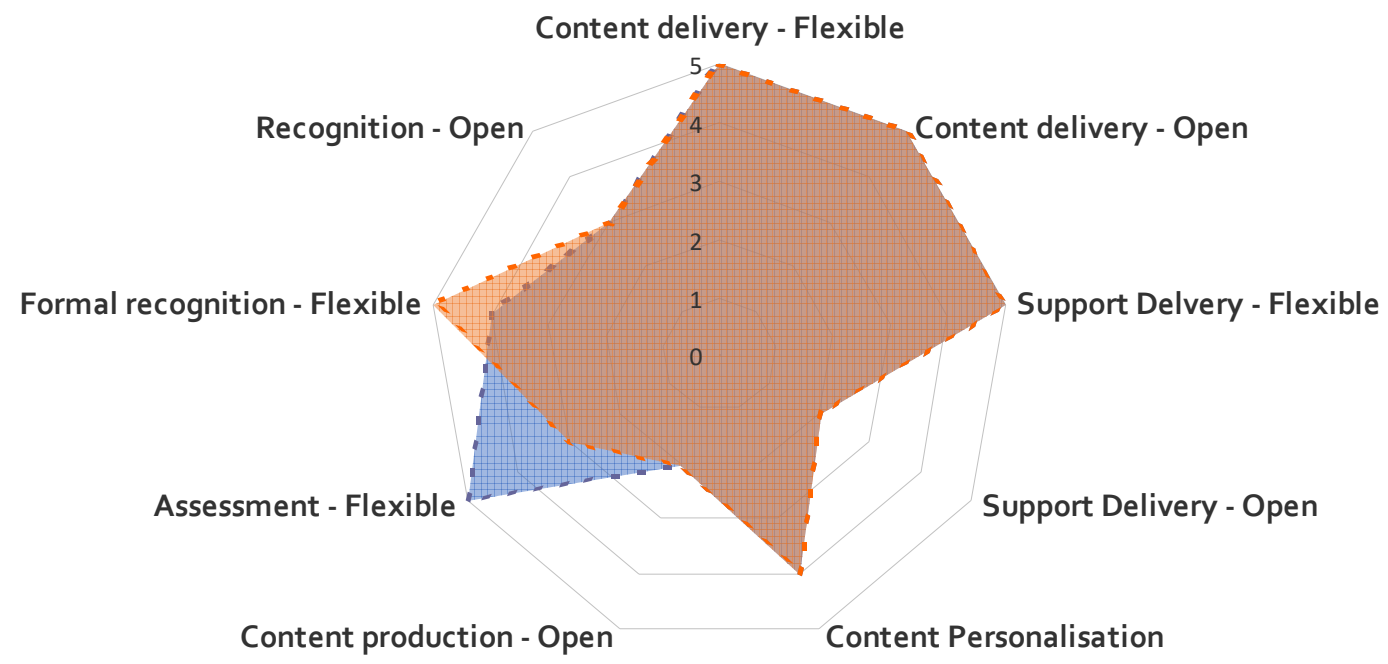

Stage 3: The institutional teams had the opportunity to share their OOFAT profiles. The visualisations illuminated institutional priorities as well as common areas of interest that could become the bridges for continued inter-institutional collaboration and a potential common flexible pathway for joined-up professional development. Using the OOFAT model and the institutional profiles in this way, helped the institutional teams to identify how their own institutional offer will be unique and distinct and how they could work with the partner institutions to join up efforts based on common priorities and areas of interest.

International Journal of Management and Applied Research, 2020, Vol. 7, No. 3 


\section{Development of a Shared Vision for Flexible Inter-Institutional Professional Development using the OOFAT Model}

The design workshop allowed the three institutional teams to identify some "binding glue", that is particular areas of activity that can support the local and collaborative enhancement approaches that are already underway and that can be incorporated into the development of the proposed flexible pathways approach to professional development. Three areas of mutual interest emerged: firstly, a recognition of the importance of building on existing peer networks and communities in the region, including regional 'conversations' and enhancing the inter-institutional peer observation network. All recognised the significance of these peer-led, in/non-formal practice-sharing opportunities and are keen that they should be harnessed and built upon in the design of the new professional development pathways. Secondly, participants recognised the potential for a shared pathway to recognition across the region, potentially through the collaborative development of a module to recognise informal and non-formal professional development (similar to the FLEX modules offered by Manchester Metropolitan University). Each institution proposes to accredit this module locally, to allow for alignment with existing professional development programmes and offerings. Finally, the OOFAT model highlighted the shared interest in the potential of e-portfolios and mentors to support professional development to enhance academic practice. All three institutional teams committed to exploring the opportunities for a more collaborative inter-institutional approach to building capacity in these areas.

\section{Methodology}

A narrative reflective approach was used to explore the impact of the OOFAT model on enhancing the openness and flexibility of an inter-institutional professional development provision for all those who teach. Narrative inquiry provides opportunities for participants to construct stories of their experiences through reflection; the researcher then formulates meaning from the stories of the participants experiences (Connelly and Clandinin 1990). This facilitates the exploration of the personal, social and political factors that may be interconnected to affect a person's experience (Connelly and Clandinin 1990). In the context of this study, narrative inquiry was deemed an appropriate methodology as it was focused on exploring the experiences of the application of a visual model such as OOFAT practice and how it allowed the participants to construct meaning. In this study the participants moved from a field i.e. the practice of using the OOFAT model, to field texts i.e. stories and narratives of using the model, through a process of using narratives it allowed the participants to reflect how the model supported inter-institutional vision (Clandinin and Huber 2002).

During the study, one representative from each FLEXIpath partner institution was asked to produce a reflective narrative on their experiences of engaging with the OOFAT model during the workshop by responding to the following question: How did the OOFAT model work to start shaping a shared vision and a way forward to develop a strategy for flexible inter-institutional professional development across the three partner institutions? Each partner institution was asked to identify one person to produce a reflective narrative in response to this prompt on behalf of the institution,

International Journal of Management and Applied Research, 2020, Vol. 7, No. 3 


\section{Development of a Shared Vision for Flexible Inter-Institutional Professional Development using the OOFAT Model}

with a guideline of approximately 500 words suggested. The narratives were then shared with the authors who collaborated synchronously in Google Docs and Adobe Connect to analyse the data to identify themes that would assist in identifying in what way the OOFAT model influenced the project team in developing a shared vision. Pseudonyms are used to report the findings (Institution A, Institution B and Institution C). The data was analysed collectively and holistically across the three reflective institutional accounts.

\section{Analysis}

The narrative accounts were analysed using Polkinghorne's (1995) analysis of narratives approach, which involves conducting a thematic analysis, exploring the relationships between themes, identifying commonalities, translating this to general knowledge. Each narrative was analysed by two authors using Polkinghorne's methodology and compared to minimise bias. The analysis was conducted synchronously in a Google Document, following these steps:

1. Each narrative was thematically analysed by two of the authors. In a table, each author identified keywords and themes from the reflective pieces.

2. The three analyses were then examined by three of the authors for commonalities in the themes across the three institutes. In total three common themes emerged (discussed below).

3. These common themes were then colour-coded in the reflective accounts to ensure the common themes remained contextualised.

4. The results were considered in light of the purposes of the OOFAT model and its implications for practice.

The analysis aimed to uncover how the OOFAT model can support the social, cultural (institutional) and physical contexts of both the collective and individual needs of HEIs in sustaining open and flexible professional development between three different HEIs. This aligns to Clandinin and Huber's (2002) places for narrative, which they conceptualise around the following three domains: (i) Temporality, that is exploring the context of time on the experience, for example the past, present and future perceptions of inter-institutional PD; (ii) Sociality, which is the personal and social meaning e.g. hopes, feelings, desires for inter-institutional PD using the OOFAT model; and (iii) Place, that is the physical place where the experience is lived e.g. the visualisation process, the objects used, and how the participants engaged with these. Our findings were translated to general knowledge through their exploration in terms of the applicability of the OOFAT model to allow those interested in inter-institutional professional development to offer a more 'open' and flexible approach.

\section{Findings}

The evaluation of the workshop and particularly the use of the OOFAT model through the institutional reflective accounts helped us respond to the question set at the outset: How did the use of the OOFAT model work to start shaping a shared vision and a way forward to develop a strategy for flexible inter-institutional professional development

International Journal of Management and Applied Research, 2020, Vol. 7, No. 3 


\section{Development of a Shared Vision for Flexible Inter-Institutional Professional Development using the OOFAT Model}

within the three Higher Education institutions in the Midwest region? Through the analysis of the three institutional reflective accounts three themes emerged, discussed below.

Facilitating structured and focused discussions

The evidence suggests that the OOFAT model and its dimensions helped scaffold the discussion that unfolded during the workshop with colleagues from the three participating institutions. Institution A says characteristically:

The OOFAT model allowed us to have a structured conversation, using the various dimensions of openness to shape our conversation. In our institution, we have had many discussions about what we want the 'future' of professional development to look like, but it had remained somewhat high level and aspirational. We had struggled to pin it down or tease it out. Working around the various dimensions of the model, we asked ourselves questions like 'To what extent do we want participants to be able to personalise content?' and 'How flexible do we want the assessment to be, in terms of focus and deadlines?'. This led to rich and robust discussions where we considered the extent of openness and flexibility that would work best for our context, bearing in mind institutional policies and practice.

The OOFAT model provided focus and openness to engage in robust and in-depth discussions and debates using this visual approach. The critique of existing models as defined and reported in Orr, Weller and Farrow (2019) was valuable for participants in the workshop to reflect on their own institutional positionality. Institution B, for example, noted that:

In the first instance, the 'speed chat' introducing each of the designs was useful in familiarising participants with the features of the model and different patterns/variations of the model. It prompted participants to consider their respective institutions and where they may lie within these models. It allowed participants to think about their institutions in terms of content, delivery and recognition, which led to quite a focused discussion.

Furthermore, the construction of institutional OOFAT models by participating institutions was seen as a vital part of this process to gain insights into their own position as well as these of their partners. Institution $\mathrm{C}$ stated the following: OOFAT created an opportunity for us to work in direct consultation with project members to better understand their requirements within the project. One of the highlights of the process was viewing the partners' dimensions graphs and seeing the similarity in priorities.

The visual representations created as outputs of the structured discussions that took place during the workshop were of value to move the conversations and the plans for the future forward. These findings suggest that the OOFAT model seems to have been an effective tool for the project team to get a better understanding of the situation in the participating institutions. Therefore, confirming the value of frameworks more broadly as a tool for understanding the nature of interactions and communities (Conole et al. 2011).

International Journal of Management and Applied Research, 2020, Vol. 7, No. 3 


\section{Development of a Shared Vision for Flexible Inter-Institutional Professional Development using the OOFAT Model}

Emergence of similarities and differences

Respondents also noted the usefulness of the OOFAT model for identifying a common/shared vision, while also clearly highlighting differing priorities among the three partner institutions. All three institutions commented favourably on the significance of the model for enabling the efficient identification of shared priorities; as Institution A stated:

The OOFAT model - and discursive activities facilitated - allowed for each of the three partner institutions to clearly identify our shared priorities. In particular, the visual nature of the model was particularly helpful; in a very short space of time, the overlaps and mutual areas of interest were apparent.

Likewise, Institution $\mathrm{C}$ noted that the "the process afforded [...] the opportunity to formally identify our similarities and differences based on the educational priorities in our unique teaching and learning environment".

While the identification of shared priorities is a crucial step for the development of the proposed flexible pathways approach to professional development for the three partner institutions, it is equally important that these pathways recognise the local priorities of each of the institutions. As is to be expected, each of the three institutions approach the support of professional learning for academic staff with differing emphases and approaches, and the OOFAT model ensured that these differences can be captured and articulated clearly. This was considered as follows by Institution B:

While differences are expected across three institutions of such varying contexts, the commonalities in the models came to the fore. While there is not ample time to delve into discussion on the differences, the nature of the project will ensure that these differences will be addressed in time. Indeed, this is where the most fruitful discussions may lie.

Similarly, Institution C commented that the OOFAT framework enabled a discussion that was 'understanding of each other's position'. Consequently, it appears that the OOFAT model can play a role in identifying shared priorities for institutions with regard to flexible, open and online provision, and the visual nature of the model promotes the efficient identification of these shared goals. Equally, the model allows for the identification of differing priorities and emphases between institutions, and thus recognises that openness and flexibility are subjective concepts that can be interpreted and applied differently in institutions.

Negotiating local and shared priorities

The structure of the workshop allowed participants personal time and space to articulate individual priorities, which were then negotiated with their institutional peers to form local priorities and finally with inter-institutional colleagues to form shared priorities. The impact of time, and the use of both personal and social spaces, was widely evident; this is articulated by Institution B as follows:

Working individually to map the desired model for our own respective institutions allowed time to think about what was important in our institution without having to consider the other varying contexts. Having

International Journal of Management and Applied Research, 2020, Vol. 7, No. 3 


\section{Development of a Shared Vision for Flexible Inter-Institutional Professional Development using the OOFAT Model}

completed the mapping individually, it was interesting to have another colleague from the same institution join the mapping process for our institution. Suddenly lines started to change, and while the map looked very similar, the degree to which features were rated did change as the discussion turned from what was an idea model to a more realistic model....This negotiated process of redefining the map was interesting.

In addition, the evidence illustrates that the temporal focus of the OOFAT model facilitates participants to shift their mind-set from current institutional professional development to future inter-institutional PD activities with several reflective accounts focusing on the future, for example:

We have had many discussions about what we want the 'future' of professional development to look like, but it had remained somewhat high level and aspirational (Institution A)

.... helped to facilitate a productive discussion with all three project partners in relation to the future of professional development in the Limerick region (Institution A)

Going forward this new understanding will create great synthesis within the project and allows for a culture of openness (Institution C)

Furthermore, the model allowed participants to articulate a shared vision in a short period of time, which up until the workshop had proved difficult; as encapsulated in the response from Institution A:

The OOFAT model - and discursive activities - allowed for each of the three partner institutions to clearly identify our shared priorities. In particular, the visual nature of the model was particularly helpful; in a very short space of time, the overlaps and mutual areas of interest were apparent.

The staged approach to adapting the model was invaluable in allowing participants to negotiate their personal, local and shared priorities in different contexts and at different points in time. In particular, negotiation was particularly clear when participants shared their institutional graphs, detailed by Institution $\mathrm{C}$ as follows:

One of the highlights of the process was viewing the partners' dimensions graphs and seeing the similarity in priorities. The process afforded the team the opportunity to formally identify our similarities and differences based on the educational priorities in our unique teaching and learning environment.

These findings suggest that the OOFAT model has potential to support the development of a shared vision for flexible, inter-institutional professional development in $\mathrm{HE}$ academic practice. Inter-institutional collaboration necessarily involves all partners considering project goals in the context of their own institutional practices, priorities and cultures; the visualisations created by the OOFAT model and the ensuing discussions pointed the project team towards shared priorities and allowed for the identification of project goals which were of interest and benefit to all partners.

International Journal of Management and Applied Research, 2020, Vol. 7, No. 3 


\section{Development of a Shared Vision for Flexible Inter-Institutional Professional Development using the OOFAT Model}

This points to a novel application of the OOFAT model beyond that which is was originally designed for; the OOFAT model has previously been used to capture institutional approaches to openness in Higher Education (Cervantes-Perez et al. 2019; Weller, 2020) whereas this study points to the potential of the OOFAT model to explore conceptions of openness and flexibility with regard to professional development to support academic practice in Higher Education. Furthermore, it was envisaged that the OOFAT model would support comparative analysis of digitalisation strategies and peer learning between institutions, particularly with regard to open educational practices (Orr, Weller and Farrow, 2019); however, our study suggests that the model has application in the domain of collaborative inter-institutional approaches to professional development. Our study indicates that OOFAT can certainly facilitate inter-institutional comparison, but can also act a springboard for the synthesis of individual institutional models to develop a collective visualization.

\section{Conclusions and further developments}

This paper sought to propose a response to the following question: can the OOFAT model support the development of a shared vision for flexible, inter-institutional professional development in Higher Education academic practice? Our experience suggests that OOFAT has great potential in this domain and evaluating the workshop in light of the OOFAT model brought new insights that are valuable for the project to move forward. It helped identify institutional positions and priorities and to start articulating a shared vision based on commonalities, while at the same time acknowledging institutional differences. The staged approach to adapting the model facilitated the time and space to identify individual, institutional and inter-institutional needs. This allowed participants to negotiate a shared vision based on similarities. However, it must be noted that the participants in the workshop described above have a longstanding history of collaboration and cooperation in the domain of PD to enhance academic practice and thus were committed to identifying further opportunities for inter-institutional collaboration. Whether institutions without the same legacy and knowledge of each other's institutional contexts would have as efficiently developed a shared vision for inter-institutional PD must be questioned; thus, the authors are slow to generalise the findings beyond the current context.

Nonetheless, our study suggests that should the model be adopted for use by other HEIs in a process similar to that described above, it can be used to facilitate the consideration of various stakeholder perspectives, including students, academic staff, administrative staff and management. Similar to the process adopted above, visual models could be prepared by the various stakeholders, which could then be compared as part of a process to develop a shared vision and understanding. Furthermore, there is scope to consider how the model could be used to facilitate the development of a PD strategy which focuses on openness and flexibility: for example, it might be used to firstly look at the current provision of professional development before exploring future provision of professional development. This would enable institutions to consider where they are coming from and where they aspire to be, thus enabling them to be more strategic in their provision of professional development. Cervantes-Perez et

International Journal of Management and Applied Research, 2020, Vol. 7, No. 3 


\section{Development of a Shared Vision for Flexible Inter-Institutional Professional Development using the OOFAT Model}

al. (2019) used the model to identify emerging institutional needs by using the OOFAT model to identify how their organisation evolved over a period of time. Likewise, future studies could consider how a similar approach might be adopted by using the OOFAT model to enable an individual institution (or indeed a collaborative team, as in the current study) to determine whether they are moving towards a more open or shared approach to professional development to enhance academic practice.

\section{Acknowledgements}

The FLEXIpath 'Professional Development Capacity Building in Higher Education: Extending provision for national impact through a flexible pathways approach' project is funded by the National Forum for the Enhancement of Teaching and Learning in Higher Education. The authors also wish to thank Prof. Martin Weller for his comments on a draft version of this paper.

\section{References}

1. Black, L.J. and Andersen, D.F. (2012), "Using visual representations as boundary objects to resolve conflict in collaborative model-building approaches", Systems Research \& Behavioural Science, Vol. 29, No. 2, pp. 194-208. https://doi.org/10.1002/sres.2106

2. Botham, K.A. (2018), "An analysis of the factors that affect engagement of Higher Education teachers with an institutional professional development scheme", Innovations in Education and Teaching International, Vol. 55, No. 2, pp. 176-189. https://doi.org/10.1080/14703297.2017.1407664

3. Brownell, S.E. and Tanner, K.D. (2012), "Barriers to faculty pedagogical change: lack of training, time, incentives and... tensions with professional identity?", $C B E$ Life Sciences Education, Vol. 11, No. 4 pp. 333-447. https://doi.org/10.1187/cbe.12-09-0163

4. Bryans, P. and Mavin, S. (2006), "Visual images: a technique to surface conceptions of research and researchers", Qualitative Research in Organizations and Management: an international journal, Vol. 1, No. 2, pp. 113-128. https://doi.org/10.1108/17465640610686370

5. Cervantes-Perez, F., Vadillo, G., Bucio, J. and Herrera, A. (2019), "Characterizing UNAM's Open Education system using the OOFAT model", The International Review of Research in Open and Distributed Learning, Vol. 20, No. 4, https://doi.org/10.19173/irrodl.v20i3.4108

6. Clandinin, J.D. and Huber, J. (2002), "Narrative inquiry: towards understanding life's artistry", Curriculum Inquiry, Vol. 32, No. 2, pp. 161-169. https://doi.org/10.1111/1467-873X.00220

International Journal of Management and Applied Research, 2020, Vol. 7, No. 3 
7. Connelly, M.F. and Clandinin, J.D. (1990), "Stories of experience and narrative inquiry", Educational Researcher, Vol. 19, No. 5, pp. 2-14. https://doi.org/10.3102\%2F0013189X019005002

8. Conole, G., Galley, R. and Culver, J. (2011), "Frameworks for understanding the nature of interactions, networking, and community in a social networking site for academic practice", The International Review of Research in Open and Distributed Learning, Vol. 12, No. 3, pp. 119-138. https://doi.org/10.19173/irrodl.v12i3.914

9. Ewenstein, B. and Whyte, J.K. (2007), "Visual representations as 'artefacts of knowing"', Building Research \& Information, Vol. 35, No. 2, pp. 81-89. https://doi.org/10.1080/09613210600950377

10. Fenton, E.M. (2007), "Visualising strategic change: the role and impact of process maps as boundary objects in reorganisation", European Management Journal, Vol. 25, No. 2, pp. 104-117. https://doi.org/10.1016/j.emj.2007.02.003

11. Kinchin, I.M. (2011), "Visualising knowledge structures in biology: discipline, curriculum and student understanding", Journal of Biological Education, Vol. 45, No. 4, pp. 183-189. https://doi.org/10.1080/00219266.2011.598178

12. Kinchin, I.M. (2014), "Visualising Knowledge Structures to Highlight the Articulation Between Theory and Method in Higher Education Research", in: Theory and Method in Higher Education Research (International Perspectives on Higher Education Research, Vol. 9), Emerald Group Publishing Limited, pp. 199218. https://doi.org/10.1108/S1479-3628(2013)0000009014

13. Kinchin, I.M., Cabot, L.B. and Hay, D.B. (2008), "Visualising expertise: towards an authentic pedagogy for higher education", Teaching in Higher Education, Vol. 13, No. 3, pp. 315-326. https://doi.org/10.1080/13562510802045345

14. National Forum for the Enhancement of Teaching and Learning in Higher Education (2020), Professional development capacity building in Higher Education: extending provision for national impact through a flexible pathways approach, Available from:

https://www.teachingandlearning.ie/project/professional-development-capacitybuilding-in-higher-education-extending-provision-for-national-impact-through-aflexible-pathways-approach/ [accessed 21 May 2020].

15. National Forum for the Enhancement of Teaching and Learning in Higher Education (2016), National Professional Development Framework for All Staff Who Teach in Higher Education, Available from: https://www.teachingandlearning.ie/wp-content/uploads/NF-2016-NationalProfessional-Development-Framework-for-all-Staff-Who-Teach-in-HigherEducation.pdf [accessed 21 May 2020].

International Journal of Management and Applied Research, 2020, Vol. 7, No. 3 
16. Orr, D., Weller, M. and Farrow, R. (2018), Models for open, online, flexible and technology enhance Higher Education across the globe: A comparative analysis, Norway: International Council for Distance Education. Available from: https://oofat.oerhub.net/OOFAT/wp-content/uploads/2018/04/Models-report-April2018_final.pdf [accessed 21 May 2020].

17. Orr, D., Weller, M. and Farrow, R. (2019), "How is digitalisation affecting the flexibility and openness of Higher Education provision? Results of a global survey using a new conceptual model", Journal of Interactive Media in Education, Vol. 2019, No. 1, p. 5. http://doi.org/10.5334/jime.523

18. Polkinghorne, D.E. (1995), "Narrative configuration in qualitative analysis", International Journal of Qualitative Studies in Education, Vol. 8, No. 1, pp. 5-23. https://doi.org/10.1080/0951839950080103

19. Sidner, C.L. (1994), "Negotiation in collaborative activity: a discourse analysis", Knowledge-Based Systems, Vol. 7, No. 4, pp. 265-267. https://doi.org/10.1016/0950-7051(94)90038-8

20. Swaab, R.I., Postmes, T., Neijens, P., Kiers, M.H. and Dumay, A.C.M. (2002), "Multiparty negotiation support: the role of visualization's influence on the development of shared mental models", Journal of Management Information Systems, Vol. $19, \quad$ No. $1, \quad$ pp. $129-150$. https://doi.org/10.1080/07421222.2002.11045708

21. Teräs, H. (2016) "Collaborative online professional development for teachers in higher education", Professional Development in Education, Vol. 42, No. 2, pp. 258-275. https://doi.org/10.1080/19415257.2014.961094

22. Travaglia, J.F., Nugus, P.I., Greenfield, D., Westbrook, J.I. and Braithwaite, J. (2011), "Visualising differences in professionals' perspectives on quality and safety", BMJ Quality and Safety, Vol. 21, No. 9, pp. 778-783. https://doi.org/10.1136/bmjqs-2011-051755

23. Van Leeuwen, T. (2008), Discourse and Practice: new tools for Critical Discourse Analysis, Oxford: Oxford University Press. https://doi.org/10.1093/acprof:oso/9780195323306.001.0001

24. Weller, M. (2020), "Open and free access to education for all”, In: Burgos D. (eds) Radical Solutions and Open Science. Lecture Notes in Educational Technology, Singapore: Springer Singapore, pp. 1-15. https://doi.org/10.1007/978-981-15-42763_1

International Journal of Management and Applied Research, 2020, Vol. 7, No. 3 